\title{
Is the Goat a New Host for the G3 Indian Buffalo Strain of Echinococcus granulosus?
}

\author{
Pietro Calderini, ${ }^{1}$ Simona Gabrielli, ${ }^{2}$ and Gabriella Cancrini ${ }^{2}$ \\ ${ }^{1}$ Sezione di Rieti, Istituto Zooprofilattico Sperimentale Delle Regioni Lazio e Toscana, V. Tancia 21, \\ 02100 Rieti, Italy \\ ${ }^{2}$ Dipartimento di Sanità Pubblica e Malattie Infettive, Sapienza Università di Roma, P. le Aldo Moro 2, \\ 00185 Roma, Italy \\ Correspondence should be addressed to Pietro Calderini, pietro.calderini@izslt.it \\ Received 1 February 2012; Accepted 5 March 2012
}

Academic Editors: M. Brunanska, M. F. Cellier, B. Chen, L. Floeter Winter, E. Gotuzzo, and R. Hasan

Copyright ( $) 2012$ Pietro Calderini et al. This is an open access article distributed under the Creative Commons Attribution License, which permits unrestricted use, distribution, and reproduction in any medium, provided the original work is properly cited.

\begin{abstract}
Four goats bred in Central Italy (province of Rieti) revealed, in the liver, metacestodes of Echinococcus granulosus. The cysts, unilocular and fertile, were examined by microscopy and molecular diagnostics. Morphological data on the rostellar hooks are in agreement with the original description of the strain found in buffaloes and are largely compatible with those reported in Europe for cattle and humans. Specific PCR followed by DNA sequencing of the mitochondrial cox1 gene revealed for all the isolates $99.5 \%$ identity to the reference strain G3 genotype and $99.3 \%$ and $99.1 \%$ to G2 and G1, respectively. Further genetic markers (nad1 and $12 \mathrm{~S}$ rRNA) confirmed the identity of the goat isolates to the G3 strain. This genotype, here reported for the first time in goats, proved to have a wider than previously supposed host range, therefore its relevance in human hydatidosis is expected to be more often evidenced.
\end{abstract}

\section{Introduction}

Cystic echinococcosis due to Echinococcus granulosus is regarded as emerging or reemerging zoonosis also in countries of the Mediterranean basin. High endemicity of this parasite depends on extensive sheep farming; in fact, it is mainly transmitted in a cycle between dog definitive host that harbours the small intestinal tapeworm and livestock (especially sheep) after the latter ingests the microscopic eggs while grazing pastures that are contaminated with dog faeces. However, several other domestic and wild herbivores/omnivores and carnivores (like wolf and fox) can be involved in the parasite transmission [1]. Humans became exposed to the eggs of the tapeworm after close contact with an infected dog or, more often, after direct/indirect contact with its contaminated environment.

The wide host range and further differences in biology and geographical distribution may be related to the existence of an E. granulosus complex of species, as suggested by genetic studies that have evidenced a number of genetic variants [2]. Currently, E. granulosus sensu lato has been split in
E. granulosus sensu stricto (genotypes G1-G3, which also includes the lion strain E. felidis), E. equinus (genotype G4), E. ortleppi (genotype G5), and E. canadensis (genotypes G6G10) [3].

This categorization follows the pattern of biological characteristics (life-cycle pattern, host specificity, development rate, pathogenicity, antigenicity, sensitivity to drugs, transmission dynamics, epidemiology, and control of echinococcosis/cystic hydatidosis also in humans). Therefore, detailed analysis on the strains found is crucial to define biological and pathological characters of each of them and to recognize genotypes of zoonotic interest.

As for Italy, during a survey on bovine hydatidosis in Central Italy (Lazio region, province of Rieti) we recovered the common G1 sheep and the G3 Indian buffalo strains of $E$. granulosus in cattle [4] so suggesting a wider than previously supposed host range and geographical distribution of the G3 genotype. This paper aims to also report, for the first time, the occurrence of the G3 genotype in four goats (two females -4 and 5 years old — and two males- 3 and 4 years old - all bred in the wild) living in the same area. 
TABLE 1: Genes, primer sequences, and accession numbers used for genetic comparisons.

\begin{tabular}{|c|c|c|c|}
\hline Genes & Primers & Sequence $\left(5^{\prime}-3^{\prime}\right)$ & $\begin{array}{l}\text { Accession } \\
\text { numbers }\end{array}$ \\
\hline \multirow{7}{*}{$\operatorname{cox} 1$} & JB3 & TTTTTTGGGCATCCTGAGGTTTAT & G1: DQ062857 \\
\hline & \multirow{6}{*}{ JB4.5 } & \multirow[t]{6}{*}{ TAAAGAAAGAACATAATGAAAATG } & G2: $\overline{M 84662}$ \\
\hline & & & G3: $\underline{\text { M84663 }}$ \\
\hline & & & $\mathrm{G} 4: \underline{\mathrm{M} 84664}$ \\
\hline & & & G5: $\overline{\mathrm{M} 84665}$ \\
\hline & & & G6: $\overline{\mathrm{M} 84666}$ \\
\hline & & & G7: $\underline{\text { M84667 }}$ \\
\hline \multirow{2}{*}{$12 \mathrm{~S}$} & p60 & TTAAGATATATGTGGTACAGGATTAGATACCC & G1: $\underline{\text { AY462129 }}$ \\
\hline & p373 & AACCGAGGGTGACGGGCGGTGTGTACC & G3: $\underline{\text { DQ822451 }}$ \\
\hline \multirow{2}{*}{ nad1 } & JB11 & AGATTCGTAAGGGGCCTAATA & G1: DQ856470 \\
\hline & JB12 & ACCACTAACTAATTCACTTTC & G3: $\underline{\text { DQ856469 }}$ \\
\hline
\end{tabular}

TABLE 2: Main features of the hydatid cysts found in goat liver.

\begin{tabular}{|c|c|c|c|c|}
\hline \multicolumn{5}{|c|}{ Animal no. } \\
\hline & 1 & 2 & 3 & 4 \\
\hline Cyst size $(\mathrm{cm})$ & $3 \times 4$ & $4 \times 6$ & $3 \times 5$ & $5 \times 6$ \\
\hline Protoscolices present & 1 & 2 & 2 & 3 \\
\hline No. of hooks & 34 & $34-35$ & $34-35$ & $34-37$ \\
\hline Arrangement of hooks & \multicolumn{4}{|c|}{ Large and small hooks alternating in 2 rows } \\
\hline \multicolumn{5}{|l|}{ Large hooks: } \\
\hline Total length $(\mu \mathrm{m})$ & 25 & 25 & 26 & 27 \\
\hline Blade length $(\mu \mathrm{m})$ & 12 & 12 & 13 & 12 \\
\hline \multicolumn{5}{|l|}{ Small hooks: } \\
\hline Total Length $(\mu \mathrm{m})$ & 20 & 19 & 22 & 21 \\
\hline Blade length $(\mu \mathrm{m})$ & 10 & 9 & 12 & 11 \\
\hline
\end{tabular}

\section{Materials and Methods}

2.1. Macro- and Microscopical Examination. Four hydatidlike cysts were removed from the liver of four goats, measured, and examined by microscopy to check for the presence of protoscolices in the fluid filling and on the cystic membrane and then to analyse the morphometric characteristics of the rostellar hooks. Protoscolices were mounted in polyvinyl lactophenol, and sufficient pressure was applied to the cover slip to cause the hooks to lie flat. The number, shape, and arrangement of rostellar hooks were assessed, and several components of both large and small hooks were measured (number of hooks, total length, and blade length) on the basis of studies that indicated these parameters as valid for identifying E. granulosus strains [5]. Measurements were made using a calibrated eyepiece micrometer under oil immersion. Part of the sample was used for biomolecular analyses aimed to assess the genotype of the isolate.

2.2. Molecular Analyses. Genomic DNA was extracted (Wizard SV Genomic DNA Purification Kit, Promega, USA) from each hydatid cyst material (protoscolices and germinal layer), and the cytochrome $\mathrm{c}$ oxidase subunits 1 (cox 1 ) gene was PCR-amplified. In addition, target sequences of the mitochondrial DNA coding for nad1 (NADH dehydrogenase subunit I) and $12 \mathrm{~S}$ rRNA were also amplified, according to protocols previously described $[6,7]$. Positive amplicons were gel-purified (NucleoSpin Extract, MachereyNagel Inc., Bethlehem, PA, USA) and directly sequenced. The obtained sequences were aligned using ClustalW with available sequences for the E. granulosus genotypes. Table 1 summarizes genes, primers, sequences used for comparisons and corresponding accession numbers in GenBank.

\section{Results}

3.1. Macro- and Microscopical Examination. Morphological analysis of the cysts removed from the liver (one from each animal) revealed that they were subspherical in shape, 3-5 $\times 4-6 \mathrm{~cm}$, unilocular, fluid-filled, and containing a different number of protoscolices (one, two, three, two) (Table 2). The rostella consisted of two rows of alternating large and small hooks (34-37 in number); large hooks were $25-27 \mu \mathrm{m}$ in total length and $12-13 \mu \mathrm{m}$ in blade length, whereas small ones were $19-22 \mu \mathrm{m}$ in total length and 9-12 $\mu \mathrm{m}$ in blade length. Figure 1 shows some large and small hooks (a) isolated from the rostellum and in preparation for counts 
TABle 3: Alignment of the variable sites in the partial cox1 mitochondrial gene of the isolates of E. granulosus sensu lato evidenced in the goats (goat 1-4) examined in Central Italy with available sequences for other genotypes deposited in GenBank (E.g1-7).

\begin{tabular}{|c|c|c|c|c|c|}
\hline \multicolumn{6}{|c|}{ Alignment positions } \\
\hline & & 1111111 & 1111222222 & 2222222233 & 3333333333 \\
\hline & 11333455 & 5670011244 & 5579123444 & 5556788900 & 0111233445 \\
\hline & 3635369316 & 7685814347 & 3945687058 & 6787623703 & 6258169582 \\
\hline GOAT1 & TAAAGTTGTC & GTGGTCGTGG & GGCGGAGGCG & GCTGATGGGT & GGATGTCGAT \\
\hline GOAT2 & $\ldots \ldots \ldots$ & $\ldots \ldots \ldots$ & $\ldots \ldots \ldots$ & $\ldots \ldots \ldots$ & $\ldots \ldots \ldots$ \\
\hline GOAT3 & $\ldots \ldots \ldots$ & $\ldots \ldots \ldots$ & $\ldots \ldots \ldots$ & $\ldots \ldots \ldots$ & $\ldots \ldots \ldots$ \\
\hline GOAT4 & $\ldots \ldots \ldots$ & $\ldots \ldots \ldots$ & $\ldots \ldots \ldots$ & $\ldots \ldots \ldots$ & $\ldots \ldots \ldots$ \\
\hline E.g1 & $\ldots \ldots \ldots$ & $. \mathrm{C} . \ldots \ldots$ & $\ldots \ldots \ldots$ &. $\mathrm{T} \ldots \ldots \ldots$ & .....Т..А \\
\hline E.g2 & $\ldots \ldots \ldots \mathrm{T}$ & $\ldots \ldots \ldots$ & $\ldots \ldots \ldots$ & $\ldots \ldots \ldots$ & ….Т..А \\
\hline E.g3 & $\ldots \ldots \ldots$ & $\ldots \ldots \ldots$ & $\ldots \ldots \ldots$ & $\ldots \ldots \ldots$ & „....Т..А \\
\hline E.g4 & .G..AG..GT & ...AAT.G.. & T.TATG.A.A & AAGT.G.T.. & TA..T.TAGA \\
\hline E.g5 & .GGT..C.GT & T.AA.TT... & ..TT.GA.TA & CG.TG.ATAC & .TT.TGT.GA \\
\hline E.g6 & ..GT.G.TGT & Т..А.ТTAAА & .TTT.GA.TA & ...TG.ATA. & ..CCT.T.GA \\
\hline E.g7 & C.GT.G.TGT & T..A.TTAAA & .TTT.GA.TA & ...TG.ATA. & ..CCT.T.GA \\
\hline
\end{tabular}

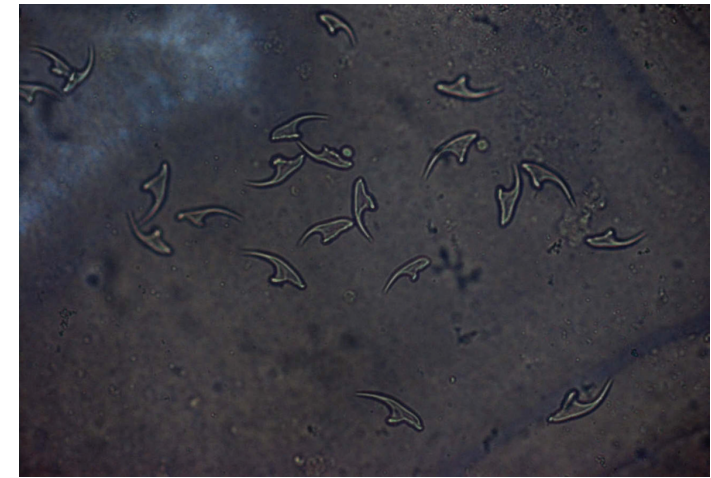

(a)

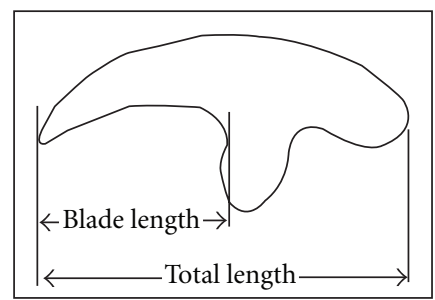

(b)

Figure 1: (a) Some large and small hooks isolated from the rostellum. (b) Diagram of measurements made on protoscolex rostrellar hooks (from [5]).

and measurements of the parameters considered as valid for identifying E. granulosus strains (b).

3.2. Molecular Analyses. Molecular identification proved the strains involved in the infection to be highly identical to the G3 buffalo strain. In fact, the analysis of the variable sites of the cox 1 sequences obtained for the four samples indicates $99.5 \%$ identity to $\mathrm{G} 3$ and $99.3 \%$ and $99.1 \%$ to $\mathrm{G} 2$ and G1, respectively (Table 3 ). The genetic identity to the other recognized species was lower: $93.4 \%$ to E. equinus, 92.9$92.7 \%$ to E. canadensis, and $92.7 \%$ to E. ortleppi. Sequencing of the nad1 and $12 \mathrm{~S}$ rRNA supports these results. Blast identity search evidenced higher identity to the G3 $(99.78 \%$ and $99.64 \%$, resp.) than to G1 strain (99.30\% and $98.93 \%$, resp.).

\section{Discussion}

To the best of our knowledge, strains to date reported in goats are the sheep strain G1 (widely distributed), the cattle
G5 and the pig G7 strains (present also in Europe), and the camel strain G6, probably absent from Europe [6, 8-10]. Thus far the G3 genotype, the "Indian buffalo strain," has been further found by us in Italy in a few sheep and cattle in Lazio [11], in only one cow in Abruzzo [12], in cattle and water buffaloes in Campania [13-15] and in bovines of the same area where these positive goats were bred [4], but never in goats. Hence, the G3 genotype confirms an extra-India geographical distribution and in Italy demonstrates that other animals are suitable hosts and can act as intermediate hosts. Even people are included among the G3 strain hosts [16]; therefore this genotype could be more often evidenced in human hydatidosis, and the importance of genotyping the isolates of E. granulosus has to be stressed in order to assess the contribution of each strain to the epidemiology of human hydatidosis.

The amount of genetic variation among the three genotypes belonging to E. granulosus s.s. is very low, and it has been hypothesized that the G3 Indian buffalo strain may be a variant of the common sheep strain G1 or closely 
related groups. However, it has been demonstrated that, even if cox1, rrnS, nad1 genes [17] and heteroduplex comparison of a microsatellite from the U1 snRNA genes [18] fail to differentiate G1 and G2 strains, the first two aforementioned genes point out a significant genetic differentiation between G1 and G3 genotypes, with fixed nucleotide substitutions, and allow their discrimination [7]. To rapidly differentiate G1 from G2/G3, a real-time PCR protocol that uses as marker the $12 \mathrm{~S}$ mtDNA gene has been recently designed [19], which, however, do not evidence mutation between G2 and G3 [16].

Therefore, it seems that G1 and G3 can be considered different strains, but available data are not conclusive and our findings cannot help. In fact, the very high genetic identity to the G3 strain of the goat isolates we found using the available more efficient molecular analyses and the morphology of the hooks, which are in general agreement with the original description [8] of the species found in buffaloes $(24-34 \mu \mathrm{m}$ and $18-30 \mu \mathrm{m})$, unfortunately are from only four cysts. If compared with morphometric data of protoscolices of $E$. granulosus from Europe [5] large hooks are more related (in total length) to that of cattle and humans, but they fit in partly (blade length) with those reported for sheep; small hooks are shorter than those of sheep and their blade (longer than in sheep) is more related to that of cattle and horse. Therefore, genetic and morphologic data on the goat isolates support the identification of the parasite found in this animal as $\mathrm{G} 3$ rather than as $\mathrm{G} 1$.

\section{Conclusions}

This is the first report of the G3 Indian buffalo strain of E. granulosus in the goat. Until G3 remains a distinct strain, as supported by recent observations $[7,19]$, goats have to be regarded as possible suitable hosts.

\section{Authors' Contribution}

G. Cancrini conceived the study, participated in its design, and helped to draft the paper. P. Calderini gave substantial contribution to conception, design and coordination of the study and carried out parasitological analyses. S. Gabrielli carried out the morphological analysis of the hooks collected and the molecular genetic studies and participated in the interpretation of the results.

\section{Acknowledgments}

The authors are grateful to Mrs. Graziella Croce for her excellent technical assistance. This study was partially supported by grants of the Italian Ministry of Health (Ricerca corrente, 2002).

\section{References}

[1] R. C. Thompson and D. P. McManus, "Aetiology: parasites and life-cycles," in WHO/OIE Manual on Echinococcosis in Humans and Animals: A Public Health Problem of Global Concern, J. Eckert, M. A. Gemmel, F. X. Meslin, and Z. S. Pawlowski, Eds., pp. 1-19, 2001.
[2] R. C. A. Thompson and D. P. McManus, "Towards a taxonomic revision of the genus Echinococcus," Trends in Parasitology, vol. 18, no. 10, pp. 452-457, 2002.

[3] M. Nakao, D. P. McManus, P. M. Schantz, P. S. Craig, and A. Ito, "A molecular phylogeny of the genus Echinococcus inferred from complete mitochondrial genomes," Parasitology, vol. 134, no. 5, pp. 713-722, 2007.

[4] P. Calderini, S. Gabrielli, A. Iori et al., "Occurrence of the G3 Indian buffalo strain of Echinococcus granulosus in cattle," Parassitologia, vol. 49, no. 4, pp. 215-217, 2007.

[5] F. Ponce Gordo and C. Cuesta Bandera, "Differentiation of Spanish strains of Echinococcus granulosus using larval rostellar hook morphometry," International Journal for Parasitology, vol. 27, no. 1, pp. 41-49, 1997.

[6] A. Varcasia, S. Canu, A. Kogkos et al., "Molecular characterization of Echinococcus granulosus in sheep and goats of Peloponnesus, Greece," Parasitology Research, vol. 101, no. 4, pp. 1135-1139, 2007.

[7] M. Busi, V. Šnábel, A. Varcasia et al., "Genetic variation within and between G1 and G3 genotypes of Echinococcus granulosus in Italy revealed by multilocus DNA sequencing," Veterinary Parasitology, vol. 150, no. 1-2, pp. 75-83, 2007.

[8] S. V. Soriano, N. B. Pierangeli, L. Pianciola et al., "Molecular characterization of Echinococcus isolates indicates goats as reservoir for Echinococcus canadensis G6 genotype in Neuquén, Patagonia Argentina," Parasitology International, vol. 59, no. 4, pp. 626-628, 2010.

[9] J. Eckert and R. C. A. Thompson, "Intraspecific variation of Echinococcus granulosus and related species with emphasis on their infectivity to humans," Acta Tropica, vol. 64, no. 1-2, pp. 19-34, 1997.

[10] K. D. Mwambete, F. Ponce-Gordo, and C. Cuesta-Bandera, "Genetic identification and host range of the Spanish strains of Echinococcus granulosus," Acta Tropica, vol. 91, no. 2, pp. 87-93, 2004.

[11] S. D’Amelio, S. Gabrielli, M. Busi et al., "Morphological and molecular characterization of taeniid metacestodes found in Central Italy," in Multidisciplinarity for Parasites, Vectors and Parasitic Diseases, S. Mas-Coma, M. D. Bargues, J. G. Esteban, and M. A. Valero, Eds., p. 314, 2004.

[12] A. Giangaspero, B. Paoletti, A. Gatti et al., "The epidemiological scenario of echinococcosis in the Abruzzo region," Parassitologia, vol. 48, no. 1-2, p. 338, 2006.

[13] F. Capuano, L. Rinaldi, M. P. Maurelli et al., "Cystic echinococcosis in water buffaloes: epidemiological survey and molecular evidence of ovine (G1) and buffalo (G3) strains," Veterinary Parasitology, vol. 137, no. 3-4, pp. 262-268, 2006.

[14] A. Casulli, M. T. Manfredi, G. La Rosa, A. R. D. Cerbo, C. Genchi, and E. Pozio, "Echinococcus ortleppi and E. granulosus G1, G2 and G3 genotypes in Italian bovines," Veterinary Parasitology, vol. 155, no. 1-2, pp. 168-172, 2008.

[15] L. Rinaldi, M. P. Maurelli, F. Capuano, A. G. Perugini, V. Veneziano, and S. Cringoli, "Molecular update on cystic echinococcosis in cattle and water buffaloes of southern Italy," Zoonoses and Public Health, vol. 55, no. 2, pp. 119-123, 2008.

[16] M. Busi, V. Snabel, C. De Liberato, and S. D’Amelio, "Molecular genotyping of Echinococcus granulosus hydatid cysts in Italy reveals the presence of three distinct genotypes," Parassitologia, vol. 46, supplement 1, p. 164, 2004.

[17] A. Obwaller, R. Schneider, J. Walochnik et al., "Echinococcus granulosus strain differentiation based on sequence heterogeneity in mitochondrial genes of cytochrome c oxidase- 1 and NADH dehydrogenase-1," Parasitology, vol. 128, no. 5, pp. 569-575, 2004. 
[18] P. A. Roratto, M. L. Bartholomei-Santos, A. M. Gutierrez, L. Kamenetzky, M. C. Rosenzvit, and A. Zaha, "Detection of genetic polymorphism among and within Echinococcus granulosus strains by heteroduplex analysis of a microsatellite from the U1 snRNA genes," GMR: Genetics and Molecular Research, vol. 5, no. 3, pp. 542-552, 2006.

[19] M. P. Maurelli, L. Rinaldi, F. Capuano, A. G. Perugini, and G. Cringoli, "Development of a real-time PCR for the differentiation of the G1 and G2/G3 genotypes of Echinococcus granulosus," Parasitology Research, vol. 105, no. 1, pp. 255-259, 2009. 

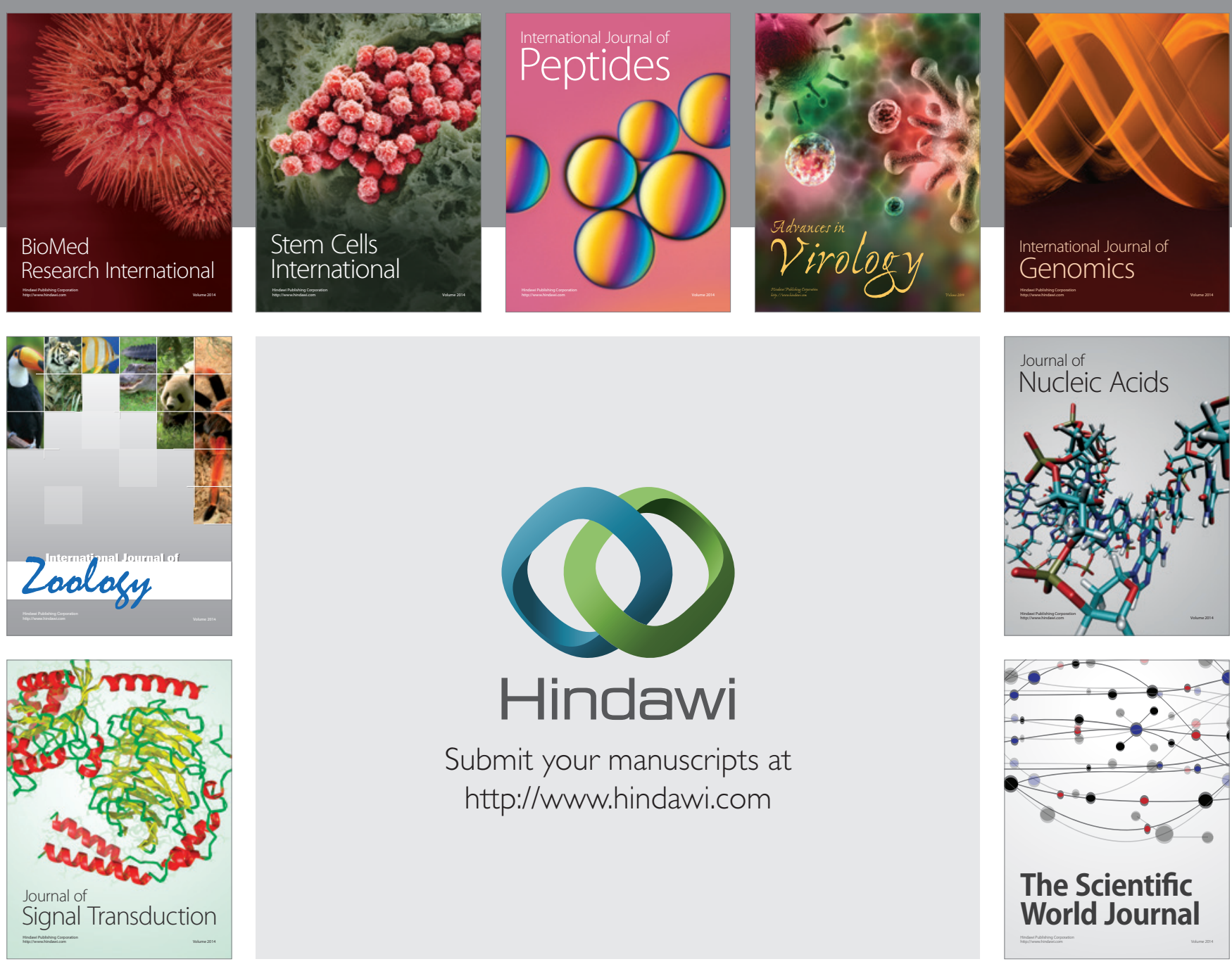

Submit your manuscripts at

http://www.hindawi.com
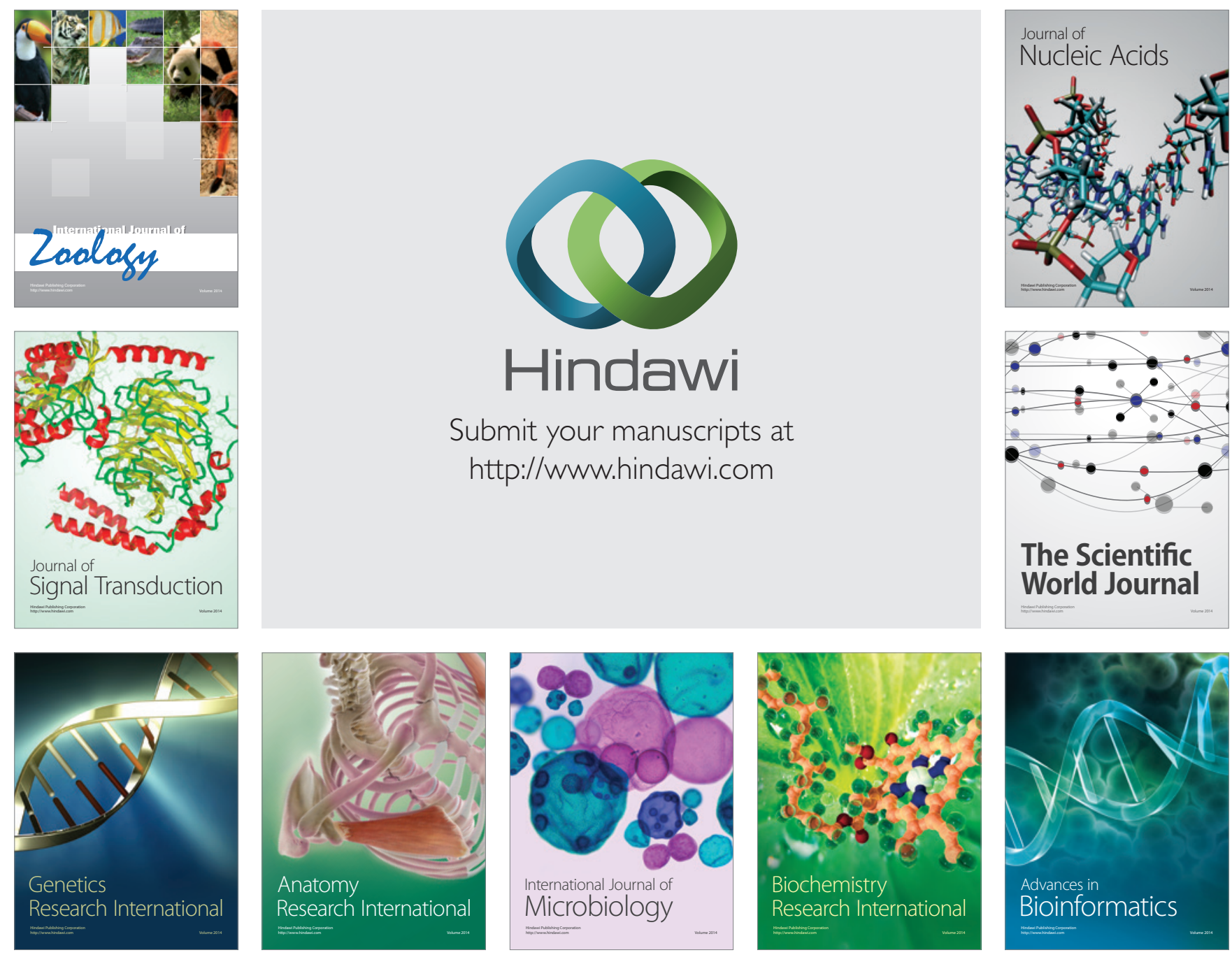

The Scientific World Journal
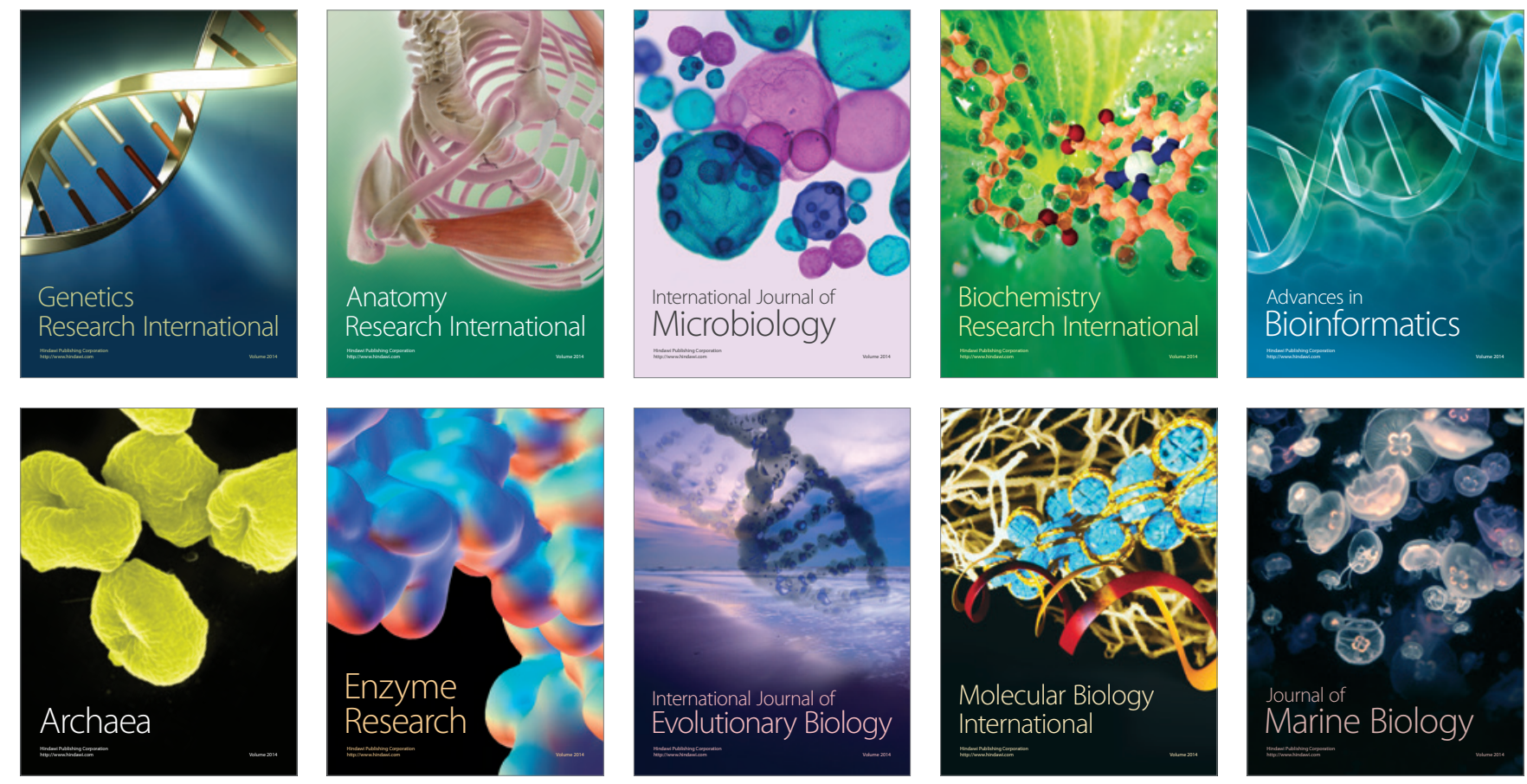